\title{
BMJ Open Young adults' perceptions of living with atopic dermatitis in relation to the concept of self-management: a qualitative study
}

\author{
Susanne Lundin (10 , ${ }^{1,2}$ Marina Jonsson, ${ }^{2,3}$ Carl-Fredrik Wahlgren, ${ }^{4}$ \\ Emma Johansson, ${ }^{4,5}$ Anna Bergstrom, ${ }^{6,7}$ Inger Kull, ${ }^{1,2}$
}

To cite: Lundin S, Jonsson M, Wahlgren C-F, et al. Young adults' perceptions of living with atopic dermatitis in relation to the concept of self-management: a qualitative study. BMJ Open 2021;11:e044777. doi:10.1136/ bmjopen-2020-044777

- Prepublication history for this paper is available online. To view these files, please visit the journal online (http://dx.doi. org/10.1136/bmjopen-2020044777).

Received 12 September 2020 Accepted 03 June 2021

Check for updates

(C) Author(s) (or their employer(s)) 2022. Re-use permitted under CC BY. Published by BMJ.

For numbered affiliations see end of article.

Correspondence to Mrs Susanne Lundin; susanne.lundin@ki.se

\section{ABSTRACT}

Objectives Learning to take control of one's health is an important part of the transition from adolescence to adulthood. This study aimed to explore young adults' perceptions of living with atopic dermatitis (AD) in relation to the concept of self-management.

Design A qualitative study with an inductive approach was performed through semistructured interviews $(n=15)$. The interviews were recorded, transcribed verbatim and analysed with systematic text condensation.

Participants Young adults (mean age 23,4 years) with persistent $A D$ in a longitudinal population-based birth cohort. To capture experience of living with persistent $A D$ (preschool/school-age onset) of different severity (mild to severe/very severe), a purposive selection was performed. In total, 15 young adults were included. Persistent AD (preschool/school-age onset) was defined as dry skin in combination with itchy rash of typical localisation in the 12 months preceding the 16-year and the 24-year followups. Severity was self-assessed using the Patient Oriented Eczema Measure.

Results Despite having experience of AD since childhood, the respondents expressed uncertainty about treatment and how it affected their bodies. Their uncertainties and feelings affected how they used topical corticosteroids.

The respondents emphasised that they perceived availability of healthcare and knowledge about treatment of $A D$ among healthcare providers to be limited. The participants did not state any experiences of support to self-management from healthcare, which affect young adults' possibilities to take full control of their $A D$ care. Conclusions Young adults with preschool/school-age onset of $A D$ are unsure how to treat and manage the disease. One explanation may be insufficient transition process.

\section{INTRODUCTION}

To optimise self-management in young people with chronic disease, there is a need for a transition process to increase knowledge and to achieve self-care skills and independence. ${ }^{12}$ To aid young adults to be autonomous and minimising dependency from parents and healthcare regarding self-management of eczema, it is important that the transition process starts at an early age (11-13 years) in collaboration with the family and all stakeholders. ${ }^{3}$ Atopic dermatitis $(\mathrm{AD})^{4}$ is a chronic disease that cannot be cured

\section{Strengths and limitations of this study}

Data from a longitudinal population-based birth cohort, with the possibility to obtaining detailed information about different phenotypes and severity of atopic dermatitis (AD) over time.

- The AD severity ranged from mild to severe/very severe as, measured by Patient Oriented Eczema Measure, a validated questionnaire.

- Equal representation of young men and women.

- The results may not be transferred to young adults with more severe $A D$ requiring specialist care.

as yet and requires daily treatment. ${ }^{5}$ In addition, it is known that $\mathrm{AD}$ affects health-related quality of life in both children and adults. ${ }^{67}$ The symptoms range from mild to very severe. ${ }^{8}$ Most individuals with $\mathrm{AD}$ have a mild disease ${ }^{69}$ However, there seems to be a discordance between patients' and physicians' assessments of severity judged using different instruments. ${ }^{10} 11$ The patients reported $\mathrm{AD}$ as more severe when their quality of life was impaired, while the physicians reported $\mathrm{AD}$ as more severe if sleep was reported to be disturbed. ${ }^{6} 7$ To ensure self-management in $\mathrm{AD}$, it is important that the individuals have sufficient skills related to treatment principles and are aware of the goals of treatment, which are to increase disease control and to extend asymptomatic periods as much as possible. ${ }^{6} 12$ This requires knowledge and education. The mainstay of treatment is the use of emollients everyday to decrease dryness and extend time to relapse of $\mathrm{AD}^{8}$ The first-line treatment of inflammation consists of topical corticosteroids (TCSs) with differing potency depending on age, localisation and severity of the symptoms. ${ }^{12}$ The chronic, recurrent nature of the disease, ${ }^{6}$ and the often time-consuming treatment, to be performed everyday, can be a challenge for individuals with $\mathrm{AD} .{ }^{13}$ Since parents have the main responsibility for the treatment of $\mathrm{AD}$ in their children, it is of importance that the parents have been trained to and understand the best 
management of the disease. ${ }^{8}$ A shift in responsibility takes place when the children reach adolescence, which requires that the adolescents gradually develop knowledge of their treatment. However, results from a Swedish populationbased birth cohort show that many adolescents with $\mathrm{AD}$ are untreated. ${ }^{14}$

In Sweden, special transition models have been developed for chronic diseases such as congenital heart diseases and diabetes (still under evaluation) ${ }^{1516}$ but- to the best of our knowledge-not for young persons with AD. According to the recently published guidelines on effective transition by the European Academy of Allergy and Clinical Immunology, ${ }^{3}$ learning to take control of treatment is an important part of the transition from adolescence to adulthood. Overall experiences of how young adults (from the general population) with $\mathrm{AD}$ manage the disease are scarcely studied. The aim of this qualitative study was, therefore, to explore young adults' perceptions of living with $\mathrm{AD}$ in relation to the concept of self-management.

\section{METHODS \\ Design}

A qualitative semistructured interview study with an inductive approach was used to capture young adults' experiences of $\mathrm{AD}$ in the concept of self-management. We followed the Consolidated Criteria for Reporting Qualitative Research guideline for conducting and reporting qualitative research. ${ }^{17}$

\section{Setting}

The present study is a part of the longitudinal populationbased cohort BAMSE (Children, Allergy, Environmental, Stockholm and Epidemiology). ${ }^{18} 19$ A purposive selection was performed to capture young adults with experience of persistent $\mathrm{AD}$ (preschool/school-age onset), with various severities (mild to severe/very severe) (table 1 ).

Moreover, we strived to capture an equal proportion of men and women with different severity of $\mathrm{AD}$. They were invited to the interview study by a clinical research nurse over the telephone. Thereafter, the first author contacted the participants, informed them about the study and asked whether they wanted to share their experiences of living with $\mathrm{AD}$.

\section{Inclusion criteria}

Young adults with persistent $\mathrm{AD}$, defined as dry skin in combination with itchy rash of typical localisation (neck/ throat, arm/leg flexures and/or wrists/ankles) in the 12 months preceding the 16-year and the 24-year follow-ups. The severity of $\mathrm{AD}$ was self-assessed as mild to severe/very severe using the Patient Oriented Eczema Measure, ${ }^{20}$ which enabled us to capture a range of experiences. The young adults who fulfilled both the questionnaire definition of $\mathrm{AD}$ (as above) and the clinical definition of $\mathrm{AD}$; visible $\mathrm{AD}$ on the neck/throat and/or flexure surfaces of the arms/legs and/or wrists/ankles and/or reported symptoms of itchy skin in the preceding week as assessed by a trained nurse were included.

Table 1 Clinical description of sex, severity and onset of AD among the participants

\begin{tabular}{|c|c|c|c|c|}
\hline Sex & $\begin{array}{l}\text { Self-assessed severity at } 16 \\
\text { years * }\end{array}$ & $\begin{array}{l}\text { Self-assessed severity at } 24 \\
\text { years * }\end{array}$ & $\begin{array}{l}\text { Onset of eczema } \\
\text { up to } 4 \text { years } †\end{array}$ & $\begin{array}{l}\text { Onset of eczema } \\
\text { from } 8 \text { years } \ddagger\end{array}$ \\
\hline M & Mild & Moderate & & $x$ \\
\hline M & Moderate & Moderate & $x$ & \\
\hline M & Mild & Moderate & $x$ & \\
\hline $\mathrm{F}$ & Mild & Mild & & $x$ \\
\hline M & Moderate & Severe/very severe & $x$ & \\
\hline M & Moderate & Mild & $x$ & \\
\hline $\mathrm{F}$ & Mild & Moderate & $x$ & \\
\hline $\mathrm{F}$ & Mild & Severe/very severe & $x$ & \\
\hline $\mathrm{F}$ & Mild & Severe/very severe & & $X$ \\
\hline M & Severe/very severe & Severe/very severe & $x$ & \\
\hline
\end{tabular}

*Patient Oriented Eczema Measure class 1, mild eczema (3-7), class 2, moderate eczema (8-16), class 3, severe/very severe eczema (17-28).

†Preschool eczema (ie, eczema onset at 1,2 or 4, not 8, 12 or 16 years of age).

¥School age eczema (ie, eczema onset at 8,12 or 16 not at 1,2 or 4 years of age).

$A D$, atopic dermatitis. 
Table 2 Interview guide

\section{Themes related to experiences of eczema,} treatment and care

Tell me what it is like to live with eczema.
Tell me what it is like when you have trouble with your
eczema.

Tell me how you usually self-treat.

\section{Follow-up questions}

Tell me what it has been like lately.

What was it like when you were a teenager? Is there any difference?

What is it like when your eczema is not troubling you?

How often do you have trouble with your eczema?

What do you think is the cause of your eczema?

How do you feel it works?

How has treatment been shown or explained to you?

What do you think about cortisone?

What do you think about moisturising cream?

Tell me about the experiences you have of healthcare in Tell me about the needs you have from healthcare due to your relation to your eczema.

eczema.

Tell me about any information you have received from healthcare regarding your eczema.

Could it have been given in any other way?

In what situations do you think about your eczema?
Do you avoid doing anything because of your eczema? Have you avoided anything in the past because of your eczema?

\section{Data collection}

All interviews were conducted at the research clinic, except two, which were conducted by telephone. The interviews were performed by the first author, an experienced dermatology nurse (SL) with no connection to the study participants before the interviews. The semistructured interview guide consisted of five themes related to living with $\mathrm{AD}$ : daily life, symptoms, treatment, care and consequences of the disease (table 2).

Probing questions were used to get a deeper understanding or explanation of some statements. To test the interview guide, one pilot interview was conducted (not included). Minor changes were then made to the interview guide. During the interview, the participants were asked if their answers were interpreted correctly. Thus, the interviewer received confirmation from the respondents. The interviews lasted on average 31 (range 23-43) min. Data collection continued until information power was judged to have been achieved. This is an approach that considers the aim, the sample specificity, the theoretical background, the quality of dialogue and the strategy for analyses. Taken together, these determine whether sufficient information power has been obtained. In total, 15 young adults, mean age 23,4 years were included (table 1), which gave us rich data covering the purpose of the study. All interviews were recorded and transcribed verbatim.

\section{Data analysis}

The text was analysed by three researchers (SL, MJ and IK) in collaboration, using systematic text condensation (STC), a thematic cross-case strategy in four steps. ${ }^{21}$ First, all interviews were read through (SL, MJ and IK), and preliminary themes were identified based on the contents of the text (SL and MJ). In the second step, meanings units were identified based on the contents of the preliminary themes and code groups were developed (SL and
$\mathrm{MJ})$. In the third step, the material from each code group was decontextualised, sorted into subgroups and the contents of the text were condensed (SL, MJ and IK). Finally, in the fourth step, data were reconceptualised, and categories made based on the essence of the young adults' experiences of eczema (SL, MJ and IK) (table 3).

The analysis was inductive, without any theory-driven approach to the phenomenon of self-management. We were open to the data and what the material told us, from an individual to a general level. In the analysis process, we tried to bracket our preconceptions to minimise the impact of our professional and clinical experiences. Using STC, with many similarities to the editing analysis style, ${ }^{22}$ we developed categories derived from the empirical data.

\section{Patient and public involvement}

The primary intention of this study was to capture young adults' perceptions of living with $\mathrm{AD}$ in relation to self-management. However, the young adults were not involved in the design of the study.

\section{RESULTS}

The respondents' perceptions of living with $\mathrm{AD}$ in the concept of self-management resulted in four categories and eight subgroups (table 3). Despite having had AD since childhood, the respondents expressed uncertainty about treatment and how it could affect their bodies. Moreover, both symptoms and treatment were described as painful. Their uncertainties and feelings affected how they used TCSs. Though the disease made itself known all the time, most of the participants stated that they had gotten used to living with eczema, it was a part of their life. The respondents emphasised that they experienced that both the accessibility and the support from healthcare providers were limited. 
Table 3 The process of analysing young adults' experiences of living with AD with systematic text condensation

\begin{tabular}{|c|c|c|c|}
\hline $\begin{array}{l}\text { Step } 1 . \\
\text { preliminary themes }\end{array}$ & $\begin{array}{l}\text { Step } 2 . \\
\text { codes }\end{array}$ & $\begin{array}{l}\text { Step } 3 . \\
\text { subgroups }\end{array}$ & $\begin{array}{l}\text { Step } 4 . \\
\text { categories }\end{array}$ \\
\hline Reminds you & $\begin{array}{l}\text { Always on my mind } \\
\text { Almost never symptom-free } \\
\text { As long as it is not visible }\end{array}$ & $\begin{array}{l}\text { Strategies } \\
\text { Acceptance }\end{array}$ & A part of life \\
\hline The care is vague & $\begin{array}{l}\text { They do not have time } \\
\text { Everyone says different things } \\
\text { Lack of information } \\
\text { The treatment does not work }\end{array}$ & $\begin{array}{l}\text { Limited availability } \\
\text { Limited support } \\
\text { Uncertainty } \\
\text { Need for information }\end{array}$ & $\begin{array}{l}\text { Difficult to get help } \\
\text { Limited knowledge }\end{array}$ \\
\hline Physical effects & $\begin{array}{l}\text { Not good for my body } \\
\text { Being careful } \\
\text { Burning and stinging }\end{array}$ & $\begin{array}{l}\text { Unnatural } \\
\text { It hurts }\end{array}$ & Impact on my body \\
\hline
\end{tabular}

\section{Limited knowledge}

Although most of the respondents had had AD from an early age, they expressed that their knowledge about its cause and treatment was limited. They had created their own treatment routines, based on their experiences and/ or what they have learnt from their parents. The young adults stated that they experienced a lack of information and directives on treatment.

\section{Uncertainty}

The young adults expressed uncertainty about the cause of their $\mathrm{AD}$, how they should treat it, what they should use to treat it, where on the body and for how long. They had not received much information about the cause or variability of the disease or about different treatments.

The doctors have been more like it will go away when you reach a certain age or something, it's just now, it will disappear, so... I'm just waiting for that age to come (9)

They felt uncertain about the treatment, if they were doing the right thing, and if the topical treatment should include or consist of cortisone.

They say cortisone is what helps, I don't know, there's no cortisone in Mometasone, as far as I know (3)

\section{Need for information}

There was a general belief among respondents that TCSs attenuated or diminished symptoms only for the moment, which reinforced the belief that they could have 'become immune' to these creams.

Most of the young adults said they treated themselves regularly, but it was clear that they were primarily referring to moisturising creams. The respondents mentioned different treatment recommendations they had been given over the years, such as not to use TCSs around the eyes and not to apply cream if it was cold outside. They also reported that they were advised to use TCSs sparingly, at most two times a week, without regards to the severity of the AD.

The respondents expressed that it would be helpful with more information and requested a guide with treatment principles, depending on the severity of the $\mathrm{AD}$.
This would be important in order to achieve independence regarding self-management of the disease.

I have understood by, like, reading and talking with different people that you should have different, like, cycles for it, but I haven't really understood how to do it, because I have not got that input from a doctor, how I should do it (14)

\section{Impact on my body}

Both symptoms and treatment of the $\mathrm{AD}$ had a painful impact on the body. Moreover, the need to use different creams to treat the $\mathrm{AD}$ was something that felt unnatural and there were thoughts on various treatments adversely affecting the body.

\section{It hurts}

Many of the respondents stated that one of the most difficult things about $\mathrm{AD}$ was that it hurts. They described the pain as a burning and stinging feeling under the skin. That pain was annoying and could prevent them from doing things that they liked to do. The pain was sometimes more trying than the itching.

Periodically, it hurt too much to put on socks and shoes... (1)

They stated that it was painful to apply cream when the $\mathrm{AD}$ was severe; they self-treated to get rid of the pain, but that hurt even more.

'It stings, of course, every time I apply the cream' (15)

\section{Unnatural}

Some of the respondents felt that it was unnatural to cover their skin with something that could affect the body negatively, especially in the case of TCSs.

That you absorb, like, products that the body is not really made to deal with (2)

They had heard that the skin could become damaged and thinner from using TCSs, which made them anxious; they, therefore, used these as little as possible. They felt 
that it was strange to use a treatment that could simultaneously damage the skin even if it decreased the AD.

I try not to use too much, plain and simple, and hope it is...that I'm like doing what you're supposed to (7)

\section{Difficult to get help}

There was a perception among the young adults that it was difficult to get help from healthcare, both making an appointment and getting the 'right' treatment. The respondents did not state any experiences of education in self-management by healthcare. Moreover, they perceived that healthcare providers did not recognise the symptoms, which resulted in insufficient and delayed treatment.

\section{Limited availability}

Even though most of the respondents had had AD all their life, they stated that they had limited contact with healthcare. It seemed to be difficult to get in touch with healthcare and get appropriate help, even when the AD was severe. Sometimes, it took several months to get an appointment and they needed to spend a lot of time trying to get in touch with the care provider. Many of the respondents could not remember the last time they had had an appointment.

It was probably in August that I contacted my dermatology department, because it [i.e., eczema] was so very bad.... and then I got an appointment for the middle of November (14)

\section{Limited support}

One respondent had experienced that the symptoms of the AD had not been taken seriously; the physician downplayed the respondent's symptoms and compared them with the more widespread symptoms of others. The participants perceived that physicians in general had limited knowledge about treatment of $\mathrm{AD}$ and the only advice they had received was to apply topical creams, without further instructions.

It seems that the GP doesn't know all that much about eczema... and just prescribes ointments that do not help (8)

Information about how they should treat the eczema also differed from physician to physician.

Some of them say 'apply it when you need to,' others say, 'apply it like several times a day,' it's like people are guessing a little, they don't have any idea, really (10)

\section{A part of life}

The respondents stated that they had become accustomed to living with $\mathrm{AD}$ and had accepted their disease. Even so, they had many strategies about how they should avoid worsening of the $\mathrm{AD}$, which required a lot of routines in the form of regular treatment, avoiding scratching and creating strategies in daily life.

\section{Strategies}

Most of the respondents thought of and were aware of their AD constantly: when it was itching, when it was visible, when they had to apply cream and so on. They had developed different strategies to avoid worsening of the $\mathrm{AD}$. The respondents perceived it as trying to experience itchiness all the time and they were aware of the importance of not scratching, even though it was difficult. Trying not to scratch required constant vigilance. Scratching was the only thing they wanted to do, but they knew it would immediately result in them being 'punished', through worsening of the AD.

That's the main thing in how I handle it, that just sitting there thinking that okay, don't scratch, don't scratch, don't scratch, don't scratch, don't scratch, it has become like a habit to try not to do it (15)

The major problem was that the AD never disappeared. They had to make choices in their daily life based on their skin condition. Most of the respondents never felt free of symptoms, which they found trying.

It's probably all the time I'd say, on different parts, it's like it moves around a bit, where it's, like, worst

The treatment of $\mathrm{AD}$ was demanding, according to the respondents. Treatment was a bit awkward and nothing they enjoyed. They had to have a regular routine and a strategy; even then, it took a long time to get rid of the AD and the respondents stated that the creams only helped for the moment.

But the eczema keeps, like, coming back anyway, even though I have this routine (9)

They always had to carry creams with them, to school, work or when they travelled, and if they forgot, they were 'punished' at once, through worsening of the AD.

Always having creams with you and applying them is not all that much fun either (3)

\section{Acceptance}

The respondents emphasised that they had gotten used to living with $\mathrm{AD}$ and had accepted their situation, even though it was hard. They did not allow AD to keep them from doing things. It was a part of their life.

It's, like, something you have, you have to learn to live with it, maybe (7)

While they had accepted their disease, they tried to avoid revealing their $\mathrm{AD}$, in so far as possible, when it was in visible places on their bodies.

I do not like it to be visible, so usually when I have these red, I usually use long sleeves, to like cover up 


\section{DISCUSSION}

This qualitative interview study of young adults with persistent $\mathrm{AD}$ from the general population demonstrated several shortcomings in the concept of self-management. Even though the young adults had experience of persistent $\mathrm{AD}$, they were unsure about how to treat the AD. The respondents expressed limited knowledge about the differences between emollients and TCSs and regarding the potency of the latter. Their uncertainty may be related to their perception of difficulties in getting help from healthcare in the terms of limited knowledge and lack of support about treatment of AD among healthcare providers. While acceptance of the disease was high, the respondents never felt completely symptom free. Altogether, this indicates an insufficiency regarding selfmanagement, including knowledge and skills in treatment principles for the disease, which may affect young adults' possibilities to take full control of their AD care.

\section{Knowledge about treatment of eczema}

The young adults' uncertainty regarding how to treat and manage the $\mathrm{AD}$ was in accordance with other studies. The uncertainty seems to be found also in self-treating adults, even if their $\mathrm{AD}$ is more severe; this can delay the start of treatment in flare-ups. ${ }^{23}$ In contrast, adolescents (12-18 years) in a qualitative study ${ }^{24}$ expressed satisfaction with the effect of their treatments, even though half of them used TCSs everyday because of low efficiency. Moreover, they had limited knowledge and incorrect beliefs about how the treatment worked. The same beliefs were seen in the present study, but the participants in our study expressed less satisfaction and more often believed that treatment, even with emollients, could harm their body.

\section{Factors of importance for self-management}

The limited contact with and difficulties in getting help from healthcare can to some extent be due to limited knowledge regarding whom to contact. Healthcare in Sweden is divided into primary care, specialist care and highly specialised care. ${ }^{25}$ Primary care is responsible for treatment and care of the most common skin diseases, such as $\mathrm{AD}$. Individuals with $\mathrm{AD}$ can buy up to $30 \mathrm{~g}$ of mild TCSs over the counter from a pharmacy; for larger amounts or more potent TGCs, a prescription is needed. The respondents' opinions that physicians had limited knowledge about treatment is in accordance with the results from a qualitative study including GPs. The GPs stated that they used a trial-and-error approach when prescribing emollients, due to the large assortment of different creams, and that they were reluctant to prescribe strong TCSs to children. ${ }^{26}$ The prescribed amounts of emollients in primary care have reportedly been unexpectedly low when compared with guidelines, which was also seen for prescription of TCSs in specialist care. ${ }^{27} 28$ To have the possibility to treat $\mathrm{AD}$ adequately, the individuals need to have access to appropriate potency and amount of TCSs and to treat the AD daily until the symptoms clear. Thereafter, the TCS therapy should be changed into proactive treatment two times a week. ${ }^{8}$

Concerns about side effects of TCSs are common. Studies including both children and adults with moderate to severe $\mathrm{AD}$ have found that approximately $50 \%$ of guardians/patients are reluctant to use TCSs. ${ }^{29}{ }^{30}$ In addition, misleading information from relatives/friends, the internet or pharmacies can lead to poor adherence. ${ }^{31} 32$

Moreover, it has been shown that concerns and uncertainties about side effects exist even among healthcare providers. ${ }^{33}$ Both GPs and pharmacists inform patients about the risks of TCSs and that they should be applied sparingly and not over long periods of time. ${ }^{34}$ This can affect the potency and amount of TCSs prescribed and strengthen the feeling among individuals with $\mathrm{AD}$ that a TCS is something to be careful with. ${ }^{35} 36$

While the young adults in the present study had gotten used to living with $\mathrm{AD}$, they stated that they needed more support. Furthermore, there seemed to be a need for repeated information about the cause, course and treatment of the disease. Several studies have stated the importance of shared decision-making, education and a written action plan, ${ }^{37-40}$ which could be useful tools to achieve independence. This is important in the process of developing autonomy in self-management and has been confirmed in a study among youths aged 14-24 years, ${ }^{41}$ which showed that $41 \%$ wanted to be more involved in their care. For adolescents with asthma, it is known that support during the transition process results in better adherence to treatment, but the healthcare transition in $\mathrm{AD}$ is less studied. ${ }^{42}$ Guidelines on asthma emphasise the importance of reviewing each patient's inhalation technique at every healthcare visit, to decrease the risk of exacerbations. ${ }^{43}$ It would be equally important to review how patients with $\mathrm{AD}$ perform self-treatment, to achieve as long symptom-free periods as possible.

\section{Strengths and limitations}

One strength of the present study was that all respondents had well-defined AD based on both prospectively recorded questionnaire data and clinical examinations. Moreover, their $\mathrm{AD}$ severity ranged from mild to very severe. Additional strengths are the credibility and transferability based on the wide range of data from the respondents, which we have exemplified using the respondents' own words.

The respondents were from the general population, which is a strength since most patients with $\mathrm{AD}$ are treated in primary care. However, the results may not be transferred to patients with more severe $\mathrm{AD}$, who may have more contact with specialist care. Still, some of the respondents in the present study had moderate to very severe $\mathrm{AD}$.

In qualitative studies, the number of participants is generally low. However, this can be compensated by a purposive selection, to get a deeper understanding of the respondents' experiences. We recruited participants with long experience of mild to very severe $\mathrm{AD}$, who wanted to 
share their experiences. The data collection gave us varied and rich data on perceptions and experiences of living with $\mathrm{AD}$. An interviewer's preconception about subjects can be both positive and negative. Deep experience can be helpful in the interview situation to promote understanding and when asking probing questions, but can also be negative, leading to the assumed understanding of what informants are saying and an assumption that the interviewer and respondent are thinking about the same thing. Preconceptions can also be negative during the analysis phase, and the bracketing of the preconceptions is a way to try to avoid these influences. Even, so this may be an unattainable goal according to Malterud. ${ }^{44}$ To minimise these effects, the analysis was carried out in collaboration with two coauthors with little or no experience in the care of patients with $\mathrm{AD}$.

\section{CONCLUSIONS}

This qualitative interview study of young adults with $A D$ from the general population demonstrated several shortcomings in self-management. Despite long experience of $\mathrm{AD}$, the young adults expressed limited knowledge and uncertainty about treatment. Their uncertainty may be related to their perception of difficulties in getting help from healthcare and of limited support, including knowledge about treatment of $\mathrm{AD}$ among healthcare providers. Altogether this may indicate shortcomings in the transition process.

\author{
Author affiliations \\ ${ }^{1}$ Sachs' Children and Youth Hospital, Södersjukhuset, Stockholm, Sweden \\ ${ }^{2}$ Department of Clinical Science and Education, Södersjukhuset, Karolinska \\ Institutet, Stockholm, Sweden \\ ${ }^{3}$ Centre for Occupational and Environmental Medicine, Stockholm County Councíl, \\ Stockholm, Sweden \\ ${ }^{4}$ Department of Dermatology and Venereology Unit, Department of Medicine Solna, \\ Karolinska Institutet, Stockholm, Sweden \\ ${ }^{5}$ Department of Dermatology, Karolinska Universitetssjukhuset i Solna, Stockholm, \\ Sweden \\ ${ }^{6}$ Centre for Occupational and Environmental Medicine, Stockholm County Council, \\ Stockholm, Sweden \\ ${ }^{7}$ Institute of Environmental Medicine, Karolinska Institutet, Stockholm, Sweden
}

Acknowledgements We thank all the participants in the BAMSE cohort, and all the staff involved in the study through the years.

Contributors SL, MJ and IK contributed to conception and design of the study. The interviews were managed by SL. The analysis with Systematic Text condensation was conducted by SL, MJ and IK in collaboration. Drafting of the manuscript was conducted by SL with support of IK, C-FW, EJ and AB. All authors participated in critical revision of the manuscript, provided important intellectual input and approved the final version.

Funding Funding for this study was provided by the Swedish Asthma and Allergy Association, grant/award number 2017-0007.

Disclaimer The funder has not been involved in the design and conduct of the study; collection, management, analysis, and interpretation of the data; preparation, review, or approval of the manuscript; and decision to submit the manuscript for publication.

Competing interests EJ reports personal lecture fees from Sanofi-Genzyme, LEO Pharma, Novartis, and ACO. EJ and SL has been part of the advisory board at Sanofi-Genzyme.
Patient and public involvement Patients and/or the public were not involved in the design, or conduct, or reporting, or dissemination plans of this research.

Patient consent for publication Not required.

Ethics approval The study was approved by the regional ethical review board at Karolinska Institutet, Stockholm (approval number 2016/1380-31-2, 2017/39532). All participants gave informed consent, 13 with written consent and two by telephone.

Provenance and peer review Not commissioned; externally peer reviewed.

Data availability statement No data are available. Audio files and transcribed text has been deposited anonymously at the BAMSE-secretariat, Institute of Environmental Medicine at Karolinska Institutet, Stockholm, Sweden.

Open access This is an open access article distributed in accordance with the Creative Commons Attribution 4.0 Unported (CC BY 4.0) license, which permits others to copy, redistribute, remix, transform and build upon this work for any purpose, provided the original work is properly cited, a link to the licence is given, and indication of whether changes were made. See: https://creativecommons.org/ licenses/by/4.0/.

ORCID iD

Susanne Lundin http://orcid.org/0000-0003-3193-4722

\section{REFERENCES}

1 Gabriel P, McManus M, Rogers K, et al. Outcome evidence for structured pediatric to adult health care transition interventions: a systematic review. J Pediatr 2017;188:263-9.

2 Schmidt A, llango SM, McManus MA, et al. Outcomes of pediatric to adult health care transition interventions: an updated systematic review. J Pediatr Nurs 2020;51:92-107.

3 Roberts G, Vazquez-Ortiz M, Knibb R, et al. EAACl guidelines on the effective transition of adolescents and young adults with allergy and asthma. Allergy 2020;75:2734-52.

4 Kantor R, Thyssen JP, Paller AS, et al. Atopic dermatitis, atopic eczema, or eczema? A systematic review, meta-analysis, and recommendation for uniform use of 'atopic dermatitis'. Allergy 2016;71:1480-5.

5 Bieber T. Atopic dermatitis. Ann Dermatol 2010;22:125-37.

6 Weidinger S, Novak N. Atopic dermatitis. Lancet 2016;387:1109-22.

7 Grant L, Seiding Larsen L, Trennery C, et al. Conceptual model to illustrate the symptom experience and humanistic burden associated with atopic dermatitis in adults and adolescents. Dermatitis 2019;30:247-54.

8 Wollenberg A, Barbarot S, Bieber T, et al. Consensus-Based European guidelines for treatment of atopic eczema (atopic dermatitis) in adults and children: Part I. J Eur Acad Dermatol Venereol 2018;32:657-82.

9 Ballardini N, Kull I, Söderhäll C, et al. Eczema severity in preadolescent children and its relation to sex, filaggrin mutations, asthma, rhinitis, aggravating factors and topical treatment: a report from the BAMSE birth cohort. Br J Dermatol 2013;168:588-94.

10 Wei W, Anderson P, Gadkari A, et al. Discordance between physicianand patient-reported disease severity in adults with atopic dermatitis: a US cross-sectional survey. Am J Clin Dermatol 2017;18:825-35.

11 Holm EA, Wulf HC, Stegmann H, et al. Life quality assessment among patients with atopic eczema. Br J Dermatol 2006;154:719-25.

12 Weidinger S, Beck LA, Bieber T, et al. Atopic dermatitis. Nat Rev Dis Primers 2018;4:1.

13 Santer M, Burgess H, Yardley L, et al. Managing childhood eczema: qualitative study exploring carers' experiences of barriers and facilitators to treatment adherence. J Adv Nurs 2013;69:2493-501.

14 Lundin S, Wahlgren CF, Bergström A, et al. Use of emollients and topical glucocorticoids among adolescents with eczema: data from the population-based birth cohort BAMSE. Br J Dermatol 2018;179:709-16.

15 Acuña Mora M, Saarijärvi M, Sparud-Lundin C, et al. Empowering Young Persons with Congenital Heart Disease: Using Intervention Mapping to Develop a Transition Program - The STEPSTONES Project. J Pediatr Nurs 2020;50:e8-17.

16 Brorsson AL, Bratt E-L, Moons P, et al. Randomised controlled trial of a person-centred transition programme for adolescents with type 1 diabetes (STEPSTONES-DIAB): a study protocol. BMJ Open 2020;10:e036496.

17 Tong A, Sainsbury P, Craig J. Consolidated criteria for reporting qualitative research (COREQ): a 32-item checklist for interviews and focus groups. Int J Qual Health Care 2007;19:349-57. 
18 Wickman M, Kull I, Pershagen G, et al. The BAMSE project: presentation of a prospective longitudinal birth cohort study. Pediatr Allergy Immunol 2002;13:11-13.

19 Ödling M, Andersson N, Hallberg J, et al. A gap between asthma guidelines and management for adolescents and young adults. $J$ Allergy Clin Immunol Pract 2020;8:3056-65.

20 Charman CR, Venn AJ, Williams HC. The patient-oriented eczema measure: development and initial validation of a new tool for measuring atopic eczema severity from the patients' perspective. Arch Dermatol 2004;140:1513-9.

21 Malterud K. Systematic text condensation: a strategy for qualitative analysis. Scand J Public Health 2012;40:795-805.

22 Crabtree BF, Miller WL. Doing qualitative research. SAGE, 1999.

23 Ortiz de Frutos FJ, Torrelo A, de Lucas R, et al. Patient perspectives on triggers, adherence to medical recommendations, and disease control in atopic dermatitis: the DATOP study. Actas Dermosifiliogr 2014;105:487-96.

24 Kosse RC, Bouvy ML, Daanen M, et al. Adolescents' perspectives on atopic dermatitis Treatment-Experiences, preferences, and beliefs. JAMA Dermatol 2018;154:824-7.

25 Council SR. The Swedish healthcare system, 2020.

26 Le Roux E, Powell K, Banks JP, et al. Gps' experiences of diagnosing and managing childhood eczema: a qualitative study in primary care. Br J Gen Pract 2018;68:e73-80.

27 Choi JY, Dawe R, Ibbotson S, et al. Quantitative analysis of topical treatments in atopic dermatitis: unexpectedly low use of emollients and strong correlation of topical corticosteroid use both with depression and concurrent asthma. $\mathrm{Br} J$ Dermatol 2020;182:1017-25.

28 Schmitt J, Schmitt NM, Kirch W, et al. Outpatient care and medical treatment of children and adults with atopic eczema. $J$ Dtsch Dermatol Ges 2009;7:345-51.

29 Zuberbier T, Orlow SJ, Paller AS, et al. Patient perspectives on the management of atopic dermatitis. J Allergy Clin Immunol 2006;118:226-32.

30 Jung HJ, Bae JY, Kim JE, et al. Survey of disease awareness, treatment behavior and treatment satisfaction in patients with atopic dermatitis in Korea: a multicenter study. J Dermatol 2018;45:1172-80.

31 Smith SD, Farrugia LL, Harris V, et al. Evaluation of the influence of family and friends, and the Internet on patient perceptions of longterm topical corticosteroid use. J Dermatolog Treat 2017;28:642-6.
32 Smith SD, Hong E, Fearns S, et al. Corticosteroid phobia and other confounders in the treatment of childhood atopic dermatitis explored using parent focus groups. Australas J Dermatol 2010;51:168-74.

33 Bos B, Antonescu I, Osinga $\mathrm{H}$, et al. Corticosteroid phobia (corticophobia) in parents of young children with atopic dermatitis and their health care providers. Pediatr Dermatol 2019;36:100-4.

34 Farrugia LL, Lee A, Fischer G, et al. Evaluation of the influence of pharmacists and GPs on patient perceptions of long-term topical corticosteroid use. J Dermatolog Treat 2017;28:112-8.

35 Arkwright PD, Motala $\mathrm{C}$, Subramanian $\mathrm{H}$, et al. Management of difficult-to-treat atopic dermatitis. J Allergy Clin Immunol Pract 2013:1:142-51.

36 Feldman SR, Vrijens B, Gieler U, et al. Treatment adherence intervention studies in dermatology and guidance on how to support adherence. Am J Clin Dermatol 2017;18:253-71.

37 Noerreslet M, Jemec GBE, Traulsen JM. Involuntary autonomy: patients' perceptions of physicians, conventional medicines and risks in the management of atopic dermatitis. Soc Sci Med 2009;69:1409-15.

38 Stalder J-F, Bernier C, Ball A, et al. Therapeutic patient education in atopic dermatitis: worldwide experiences. Pediatr Dermatol 2013;30:329-34.

39 Müller SM, Tomaschett D, Euler S, et al. Topical corticosteroid concerns in dermatological outpatients: a cross-sectional and interventional study. Dermatology 2016;232:444-52.

40 Shi VY, Nanda S, Lee K, et al. Improving patient education with an eczema action plan: a randomized controlled trial. JAMA Dermatol 2013;149:481-3.

41 Schuiteman S, Chua K-P, Plegue MA, et al. Self-management of health care among youth: implications for policies on transitions of care. J Adolesc Health 2020;66:616-22.

42 Vazquez-Ortiz M, Angier E, Blumchen K, et al. Understanding the challenges faced by adolescents and young adults with allergic conditions: a systematic review. Allergy 2020;75:1850-80.

43 GINA gifa. Pocket guide for asthma management and prevention (for adults and children older than 5 years), 2020.

44 Malterud K. Kvalitativa metoder i medicinsk forskning : en introduktion (Qualitative methods in medical research: an introduction. Studentlitteratur, 2014. 